\title{
RUANG KREATIF KRAMAT
}

\author{
Bella Octavia Darmawan ${ }^{1)}$, Suryono Herlambang ${ }^{2)}$
}

1) Program Studi S1 Arsitektur, Fakultas Teknik, Universitas Tarumanagara, bella.315150063@stu.untar.ac.id

2) Program Studi S1 Perencanaan Wilayah dan Kota, Fakultas Teknik, Universitas Tarumanagara, suryonoh@ft.untar.ac.id

\begin{abstract}
Abstrak
Kehidupan perkotaan identik dengan rutinitas dan kesibukan tinggi dimana persaingan antar individu masyarakat terus meningkat. Rutinitas dan kesibukan yang terus terakumulasi oleh setiap individu memicu kepenatan dan mengakibatkan sikap kerja/belajar yang kurang produktif. Third place hadir untuk menyeimbangkan kehidupan masayarakat diluar rumah dan tempat kerja. Dengan begitu, third place diperlukan dalam kawasan kota besar yang disesuaikan pula dengan kebutuhan masyarakatnya. Proyek ini mendukung keseimbangan hidup masyarakat di sekitar kelurahan Kramat, Senen dengan program - program yang sesuai kebutuhan. Program yang muncul sesuai kawasan Kramat yaitu ruang kreatif karena warga sekitar yang telah menjalani profesi sebagai pengrajin ondel - ondel namun tidak tersedianya wadah untuk menyalurkan bakat tersebut. Metode perancangan meliputi teknik pengumpulan data melalui observasi dan wawancara dengan hasil yang diaplikasikan ke dalam metode perancangan tarnsformasi. Ruang Kreatif Kramat di kawasan Senen ini merupakan third place yang direncanakan untuk melayani kebutuhan masyarakat sekitar dalam bidang sosial dan kreativitas guna menjawab isu kehidupan perkotaan karena kesibukan sehari-hari. Proyek ini menyediakan beberapa fasilitas yang mewadahi kegiatan masyarakat pada pendidikan, tempat makan, dan tempat berkumpul/bersosialisasi. Proyek ini direncanakan agar semua golongan masyarakat terutama di kelurahan Kramat dapat menggunakannya sehingga bukan hanya sebagai tempat pelepas penat namun juga tempat untuk saling berinteraksi agar terjalin hubungan yang lebih kuat dalam masyarakat sehingga bisa berguna bagi kedepannya. Masyarakat pun telah menyadari dampak kerusakan alam maka proyek ini akan dirancang ramah lingkungan.
\end{abstract}

\section{Kata kunci: kramat; kreatif; third place}

\begin{abstract}
Urban life is synonymous with routine and high activity in which competition between individual communities continues to increase. The routine and busyness that continues to accumulate by each individual approves fatigue and demands less productive work / study. The third place is present to balance the lives of people outside the home and work place. That way, third place is needed in the big city area which is also adjusted to the needs of the community. This project supports the balance of life in the communities around the Kramat village, Senen with programs that suit their needs. The program that emerges according to the Kramat region is a creative space because the local residents who have a profession as ondel - ondel craftsmen but do not have a place to channel these talents. The design method includes data collection techniques through observation and interviews with the results applied to the transformation design method. Kramat Creative Place in Senen is the third place planned to serve the needs of the surrounding community in the social and creativity fields in order to address the issue of urban life due to daily busyness. This project provides several facilities that facilitate community activities in education, eating places, and meeting / socializing places. This project is planned so that all groups of people, especially in the Kramat district can use it so that it is not only a place to release fatigue but also a place to interact with each other to establish stronger relationships in the community so that it can be useful for the future. The community has also become aware of the impact of natural damage, so this project will be designed environmentally friendly.
\end{abstract}

Keywords: creative; kramat; third place 


\section{PENDAHULUAN}

Kehidupan perkotaan identik dengan rutinitas dan kesibukan tinggi dimana persaingan antar individu masyarakat terus meningkat. Rutinitas dan kesibukan yang terus terakumulasi oleh setiap individu memicu kepenatan dan mengakibatkan sikap kerja/belajar yang kurang produktif. Third place hadir untuk menyeimbangkan kehidupan masayarakat diluar rumah dan tempat kerja. Dengan begitu, third place diperlukan dalam kawasan kota besar yang disesuaikan pula dengan kebutuhan masayarakatnya.

Gelb (2015) menyatakan bahwa produktivitas individu dapat dikembangkan dengan memanfaatkan waktu diluar jam kerja. Beberapa kegiatan bermanfaat yang dapat dilakukan diluar jam kerja diantaranya:

a. Olahraga

b. Mencari inspirasi dan pengalaman baru

c. Membangun hubungan khusus

d. Menghabiskan waktu di alam

e. Melepas diri dari gadget

f. Memanfaatkan waktu sepulang kerja secara maksimal

g. Bersantai dan menjaga diri

Third place merupakan tempat yang dapat menampung kegiatan yang tertera di atas. Selain untuk mewadahi para pekerja, third place juga perlu memperhatikan kawasan yang terpilih. Demografi, kebiasaan, dan aktivitas yang terjadi pada suatu kawasan dapat dijadikan faktor penentu program-program yang sesuai kebutuhan kawasan agar tepat sasaran. Sasaran third place adalah semua golongan masyarakat tanpa batasan umur, status sosial, suku, ataupun budaya.

Perkotaan sangat padat dengan penduduk yang bermukim dan juga bekerja namun peruntukan lahan untuk tempat terbuka sangat terbatas bahkan tidak ada. Terkadang masyarakat membutuhkan ruang yang nyaman dan berbeda dari tempat tinggal dan tempat kerja agar tidak merasa bosan dan dapat mengisi ulang energi yang terpakai selama bekerja/belajar.

Third place bersifat low-cost dengan adanya area tidak berbayar yang besar agar dapat menampung sejumlah besar warga sekitar kawasan dengan keperluan yang beragam. Meskipun keperluan setiap individu masyarakat akan berbeda satu sama lain, beberapa kesamaan tetap dapat ditarik menurut citra kawasan yang bersangkutan.

Melalui pembahasan mengenai isu kehidupan perkotaan dan pentingnya third place bagi sebuah kawasan, terpilih kawasan Senen, Jakarta Pusat. Senen terkenal sebagai pusat perdagangan ibukota karena banyaknya toko - toko besar di sepanjang jalan Kramat Bunder, Kramat Raya, Kwitang, dan Senen Raya sejak awal abad 20. Proyek Senen yang dijalankan pada tahun 1960 melengkapi kawasan ini dengan pasar inpres dan juga terminal yang hingga sekarang sangat berguna bagi masyarakat dari berbagai kawasan. Proyek ini akan menjawab isu third place di Kramat, Senen, dan menangkat program yang sesuai kebutuhan kawasan.

\section{KAJIAN LITERATUR}

\section{Third place}

Dalam bukunya yang berjudul The Great Good Place, Oldenburg menyadari kurangnya kehidupan publik informal dimana pusat perkumpulan pada suatu kawasan semakin berkurang seiring perkembangan waktu. Sarana publik informal ini berfungsi untuk mendukung relaksasi bagi masyarakat karena stres di dalam sebuah sistem sosial tidak dapat dihindari dan haruslah ditangani. Jumlah sarana publik informal yang memadai akan melengkapi dan mendukung rutinitas sehari-hari. Kurangnya sarana ini akan mendorong masyarakat untuk hidup boros karena metode relaksasi yang berbeda dan cenderung mengarahkan pada hidup konsumerisme.

Istilah third place kemudian diciptakan Oldenburg sebagai tempat dimana manusia dapat bersantai dan memenuhi kesehariannya. Kehadiran third place bertujuan untuk menyeimbangkan 3 bidang pengalaman yaitu; kelokalan, sifat produktif, dan keramahan. Third 
place adalah kumpulan dari berbagai tempat publik yang melayani pengunjung (pelanggan) secara sukarela dan tidak resmi, serta pertemuan yang menyenangkan diluar rumah dan tempat kerja. Sifat third place netral, jelas, dan mudah diperoleh (dijangkau).

Karakter third place diantaranya adalah:

a. Berada pada area netral dimana masyarakat bisa datang sesukanya dan merasa nyaman berada di dalamnya

b. Bertindak menyamaratakan dimana masyarakat tidak merasakan perbedaan status sosial, semua diperlakukan setara

c. Perbincangan sebagai aktivitas utama dimana percakapan antar individu bisa menimbulkan suasana yang hidup, penuh warna, dan menarik, perbincangan akan menjadi seperti permainan yang memikat kelompok masyarakat

d. Mudah akses dan akomodasi dimana masyarakat dapat mengaksesnya sendiri kapanpun, mudah dijangkau oleh masyarakat setalah rutinaitas kesehariannya dan mampu menyediakan tempat bagi aktivitas yang tideak direncanakan, mendadak, dan tidak terstruktur

e. Memiliki pelanggan tetap meskipun awalnya merupakan pendatang baru, karena frekuensi kehadiran yang rutin, munculah regulars yang kemudian menarik / mendatangkan pengunjung lainnya sehingga tercipta keperecayaan dalam suatu kelompok masyarakat

f. Bersifat sederhana, tidak bersifat elegan, tidak bertujuan untuk memberi kesan tertentu, dan bukan untuk tujuan utama komersial

g. Bersuasana menyenangkan sehingga masyarakat dapat menikmati dirinya sendiri, selalu ingin untuk datang, membuat dan menangkap pengalaman menyenangkan kembali

h. Seperti rumah diluar rumah dimana rumah yang dimaksud adalah lingkungan yang sesuai dan menyenangkan serta pengertian bahwa rumah adalah tempat meregenerasi dan memulihkan diri.

\section{Community Center}

Community center dimaksudkan untuk menjadi pusat kegiatan yang dapat diidentifikasi untuk komunitas (masyarakat) suatu kawasan yang mampu melayani populasi 25.000 hingga 100.000 jiwa. Tempat ini bisa menampung beragam kegunaan seperti kantor kecil, akomodasi, fasilitas budaya dan hiburan, sekolah dan perpustakaan serta fungsi lain yang berorientasi lingkungan.

Menurut lacity.org, terdapat dua jenis community center yaitu:

1. Community center yang mendorong pengembangan kantor profesional, hotel, fasilitas budaya dan hiburan, di samping penggunaan yang berorientasi lingkungan.

2. Community center yang mendorong pengembangan kawasan bersamaan dengan penggunaan komersial ataupun mix-used. Pada tempat ini terjalin integrasi antara fasilitas publik dan kepemilikian privat.

Community center harus direncanakan untuk penggunaan siang dan malam hari. Jalan, penerangan jalan, dan jalur pedestrian sekitar bangunan harus tersedia dengan standar yang sepadan dengan penggunaan malam hari. Community center sebaiknya dilayani oleh transportasi umum seperti shuttle bus atau bus lokal dan membatasi penggunaan mobil karena lebih efisien. Transportasi umum utama (kereta, bus, atau keduanya) akan berkembang oleh karena keberadaan community center untuk meningkatkan akses ke dan dari sekitar kota/kawasan. Struktur parkir terpusat harus diintegrasikan dengan pengembangan privat dan publik, jika perlu.

Integrasi dan fungsi campuran di community center akan meningkatkan peluang bagi pekerja untuk tinggal di dekat tempat kerja mereka dan penduduk untuk tinggal di dekat tempat perbelanjaan. Bila hal ini tercapai, jumlah perjalanan dengan kendaraan akan berkurang dan aktivitas pejalan kaki / sepeda akan meningkat sehingga dapat mengurangi polusi udara. 


\section{Food court}

Food court umumnya merupakan plaza dalam ruangan yang terdiri dari beberapa vendor makanan dengan area untuk makan (susunan meja dan kursi). Food court dapat ditemukan di pusat perbelanjaan, bandara, dan taman. Makanan dipesan di salah satu vendor dan kemudian dibawa ke area makan. Food court mungkin juga memiliki toko-toko yang menjual makanan siap saji untuk dibawa pulang dan dipanaskan kembali, membuat food court menjadi perhentian harian bagi sebagian orang.

Susunan tempat duduk memberi pengunjung beberapa pilihan termasuk booth, kursi tinggi, ruang komunal dan bahkan ruang santai. Pemakaian dinding partisi yang kreatif memberi privasi pelanggan satu dengan yang lain. Fasilitas berupa colokan listrik dan wifi dapat dimanfaatkan pelanggan untuk keperluan bersosialisasi. Dengan semua perencanaan ini, food court menjadi tempat yang sangat sukses bagi orang - orang untuk berkumpul sekaligus makan. Pelanggan lebih suka food court dengan lingkungan yang mendukung terutama pada waktu penyajian yang tergolong cepat, harga yang terjangkau, dan suasana yang bervariasi.

\section{Kerajinan Ondel - Ondel}

Ondel - ondel tidak hanya berukuran besar yang biasa dapat ditemui saat pertunjukan khusus, masyarakat telah mengembangkan kerajinan ini dengan menggunakan material dengan ukuran yang bervariasi dan gabungan dengan benda lainnya yang bisa dijadikan sebagai suvenir. Di kampung ondel - ondel Kramat Pulo dijual ondel-ondel berukuran kecil dengan tinggi sekitar $30 \mathrm{~cm}$, yang bisa dijadikan suvenir khas Jakarta. Selain itu, banyak industri rumahan yang membuat ondel - ondel dari botol plastik bekas, pahatan kayu, sablon pakaian, lampu hias, pajangan dinding, dan sebagainya.

\section{METODE}

\section{Kerangka berpikir}

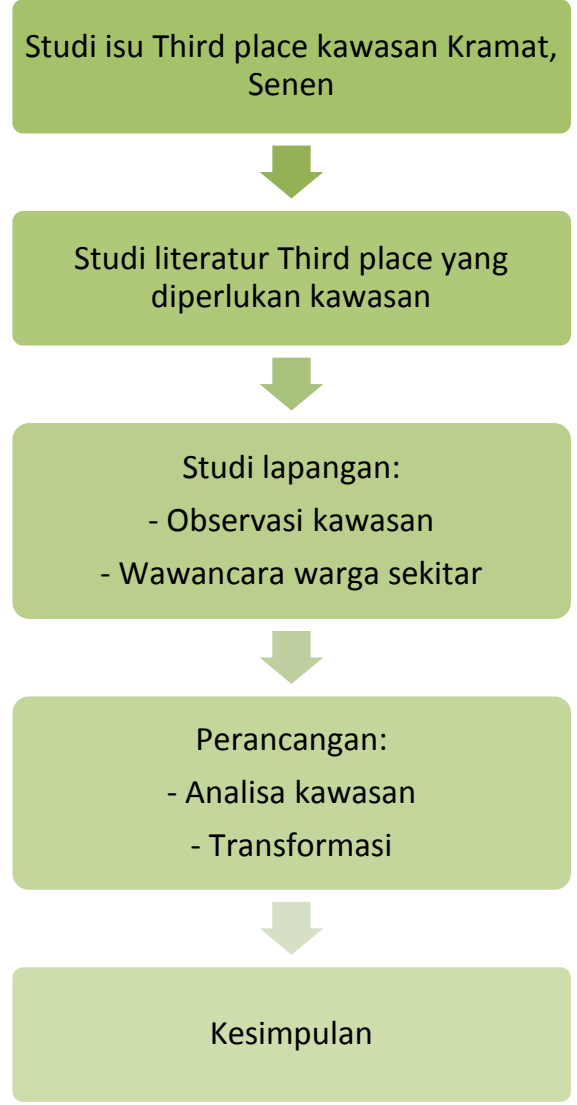

Gambar 1. Diagram kerangka berpikir Sumber: Penulis, 2019 


\section{Metode penelitian}

Metode penelitian menggunakan teknik pengumpulan data melalui observasi dan wawancara untuk memeperoleh program yang sesuai kebutuhan kawasan sehubungan dengan third place.

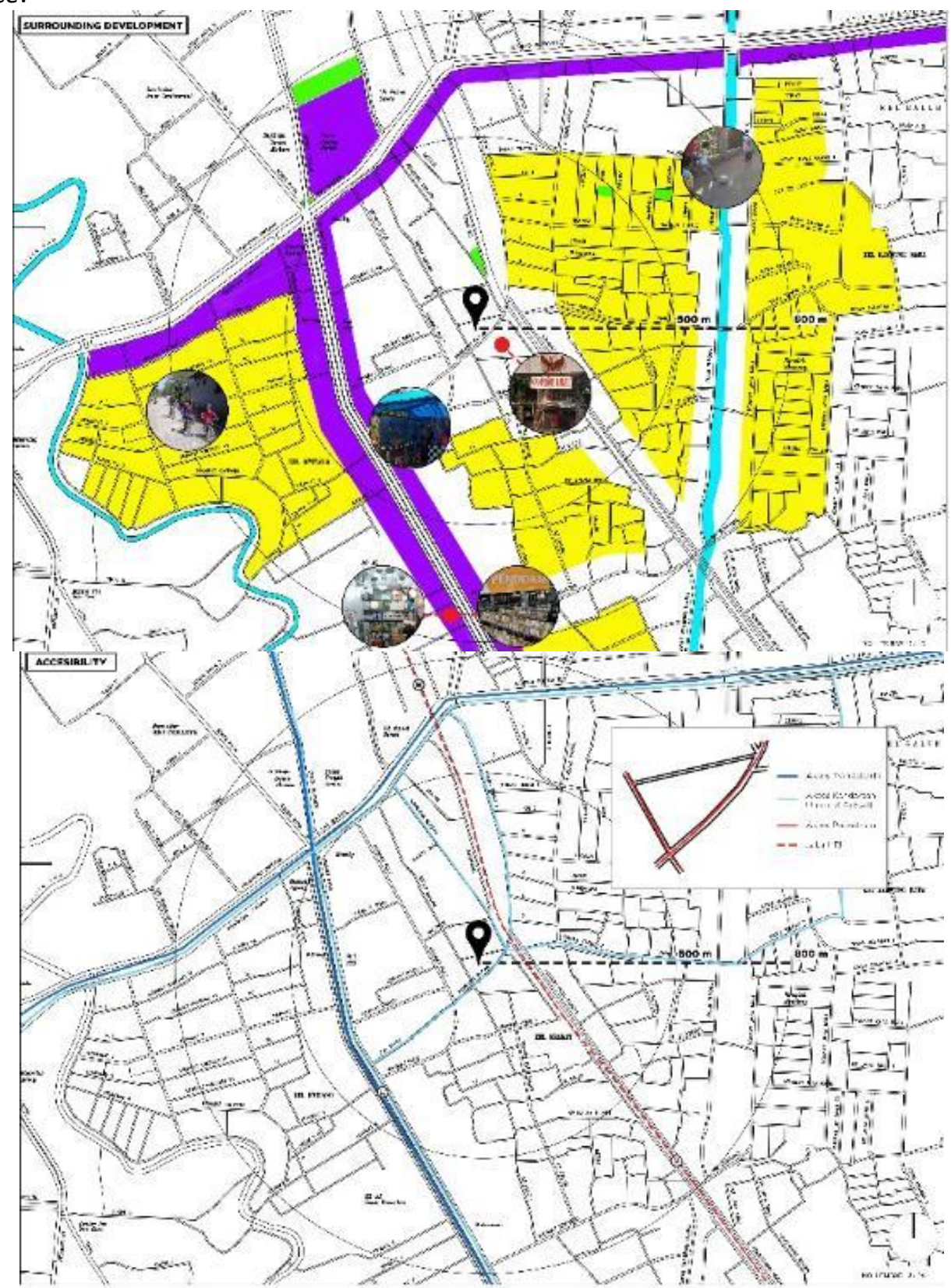

Gambar 2. Hasil observasi

Sumber: Penulis, 2019

Tapak berada pada kawasan pemukiman dan berjarak $350 \mathrm{~m}$ dari jalan utama. Akses dari jalan utama menggunakan transjakarta yang dilanjutkan dengan angkot. Tapak dikelilingi pemukiman supaya warga sekitar dapat mengunjungi proyek lebih mudah tanpa perlu menggunakan kendaraan. Melaui observasi yang telah dilakukan, kondisi eksisting dan kegiatan yang berlangsung akan menentukan program proyek. Proyek bertema third place ini akan menghadirkan program yang belum tersedia di sekitar suapaya dapat mendukung lingkungan dan memfasilitasi warga sekitar. Kampung ondel - ondel yang terletak persis di depan tapak menjadi faktor utama proyek yang menghadirkan program sesuai. Kawasan Senen yang sudah terkenal dengan pasar Kenari dimana banyak penjualan alat listrik juga memengaruhi program proyek ini. 

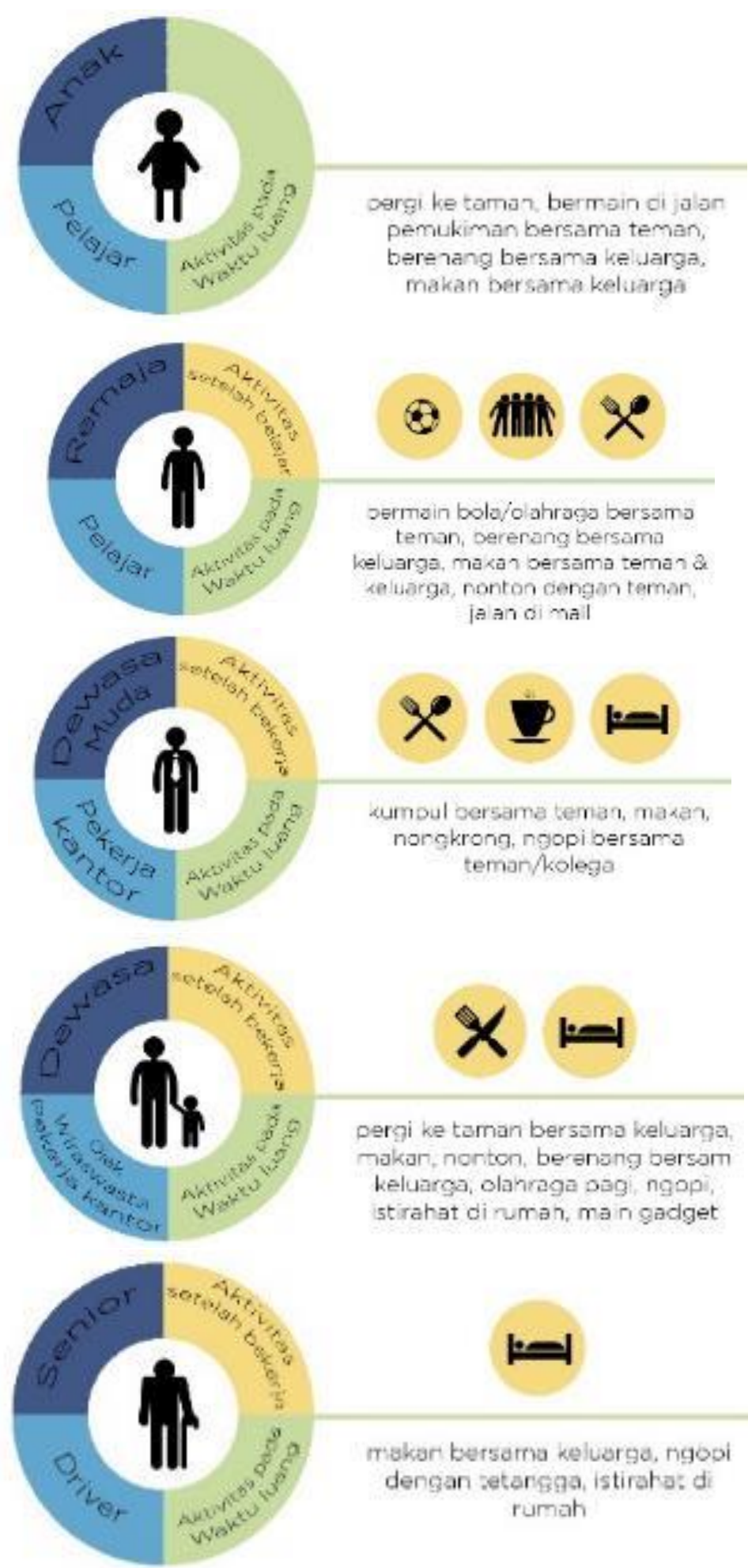

Gambar 3. Hasil wawancara

Sumber: Penulis, 2019

Selain observasi kondisi eksisting, proses wawancara dilakukan untuk mengetahui kegiatan yang biasa warga lakukan pada waktu luang. Kegiatan yang biasa dilakukan namun belum adanya wadah yang memadai juga menjadi dasar penentuan program. Wawancara dilakukan oleh beberapa narasumber semua golongan umur warga sekitar sehingga proyek ini cocok bagi semua warga dan family-friendly. 


\section{Metode desain}

Metode desain yang dipakai yaitu transformasi yang diartikan perubahan dari benda asal menjadi benda yang baru. Baik perubahan yang sudah tidak memiliki atau memperlihatkan kesamaan atau keserupaan dengan benda asalnya, maupun perubahan benda baru yang masih menunjukan petunjuk benda asalnya baik itu dengan cara digeser, dipotong, dikurangi dan di tambah pada bagian tertentu.

Transformasi terjadi melalui sintesis tapak dan konsep yang diangkat pada sebuah proyek. Pemotongan massa yang padat bertujuan agar udara dapat mengalir, penggeseran bagian bangunan mengijinkan perluasan dinding agar memperoleh sinar matahari yang cukup, penambahan bentuk geometri disesuaikan dengan kebutuhan ruang agar pembangunan maksimal, dan sebagainya. Dengan penggabungan beberapa metode transformasi, bangunan tetap harus memiliki citranya. Perancangan bentuk bangunan, konsep, dan material yang digunakan harus sesuai sehingga terlihat sebuah proyek yang satu.

\section{DISKUSI DAN HASIL}

\section{Profil kawasan}

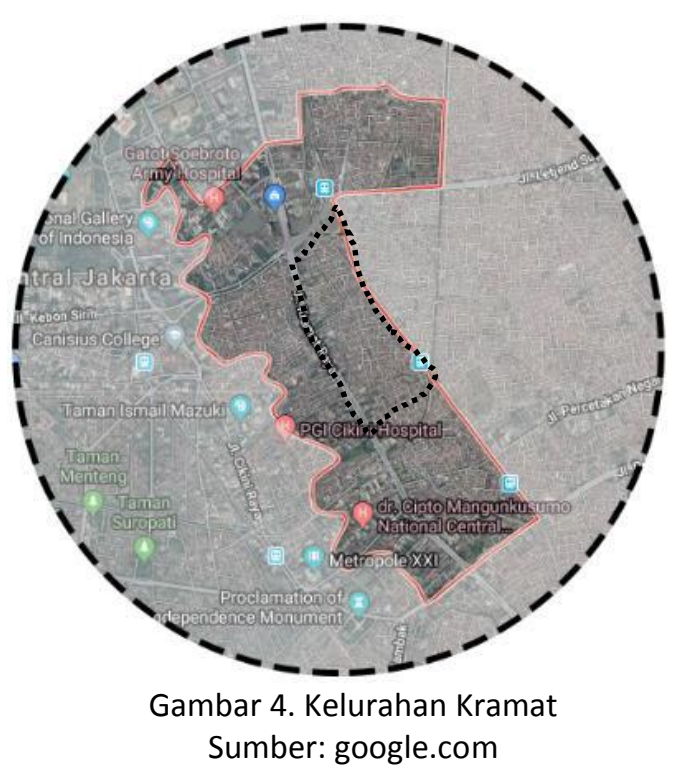

Kawasan Senen merupakan pusat perdagangan awal di ibukota. Senen terbagi menjadi 6 kelurahan yaitu: Kenari, Paseban, Kramat, Kwitang, Senen, dan Bungur. Kelurahan Kramat terpilih karena merupakan kawasan dengan karakter yang cukup spesifik yaitu kampung ondel - ondel. Kramat sendiri dipenuhi perkantoran, pemukiman, dan beberapa sarana pelayanan sosial serta terhubung moda transportasi umum yang memadai namun kehadiran third place belum tersedia.

\section{Program}

Melalui observasi dan wawancara yang telah dilakukan, muncul beberapa program yang dibutuhkan kawasan Kramat untuk semakin mendukung kehidupan warga sekitar. Program utama yaitu ruang publik dimana warga dapat berkumpul, bersosialisasi, dan menikmati pertunjukan khas ondel - ondel, serta ruang pelatihan kreativitas sehubungan dengan ondel ondel. Selain program yang sehubungan dengan kreativitas, terdapat juga program penunjang yang dapat dinikmati seluruh golongan masyarakat dari anak kecil hingga warga senior. 


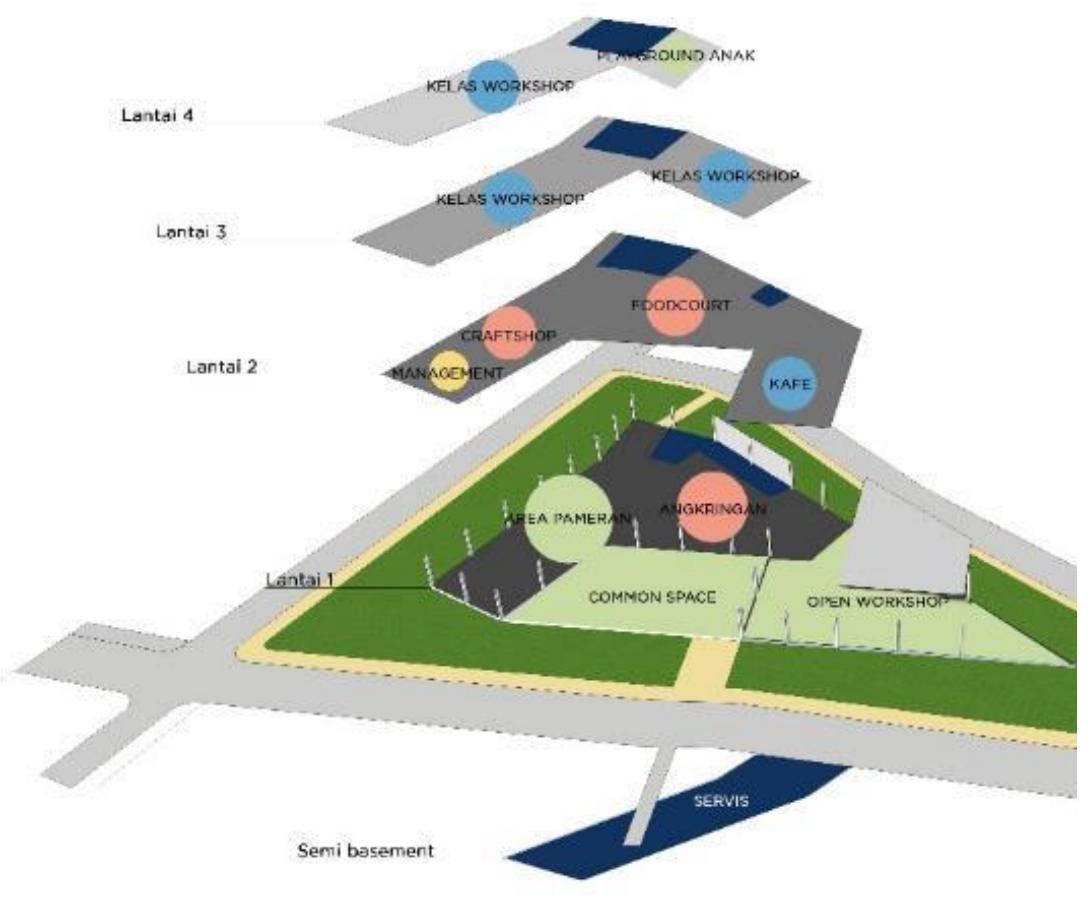

Gambar 5. Program Ruang Kreatif Kramat Sumber: Penulis, 2019

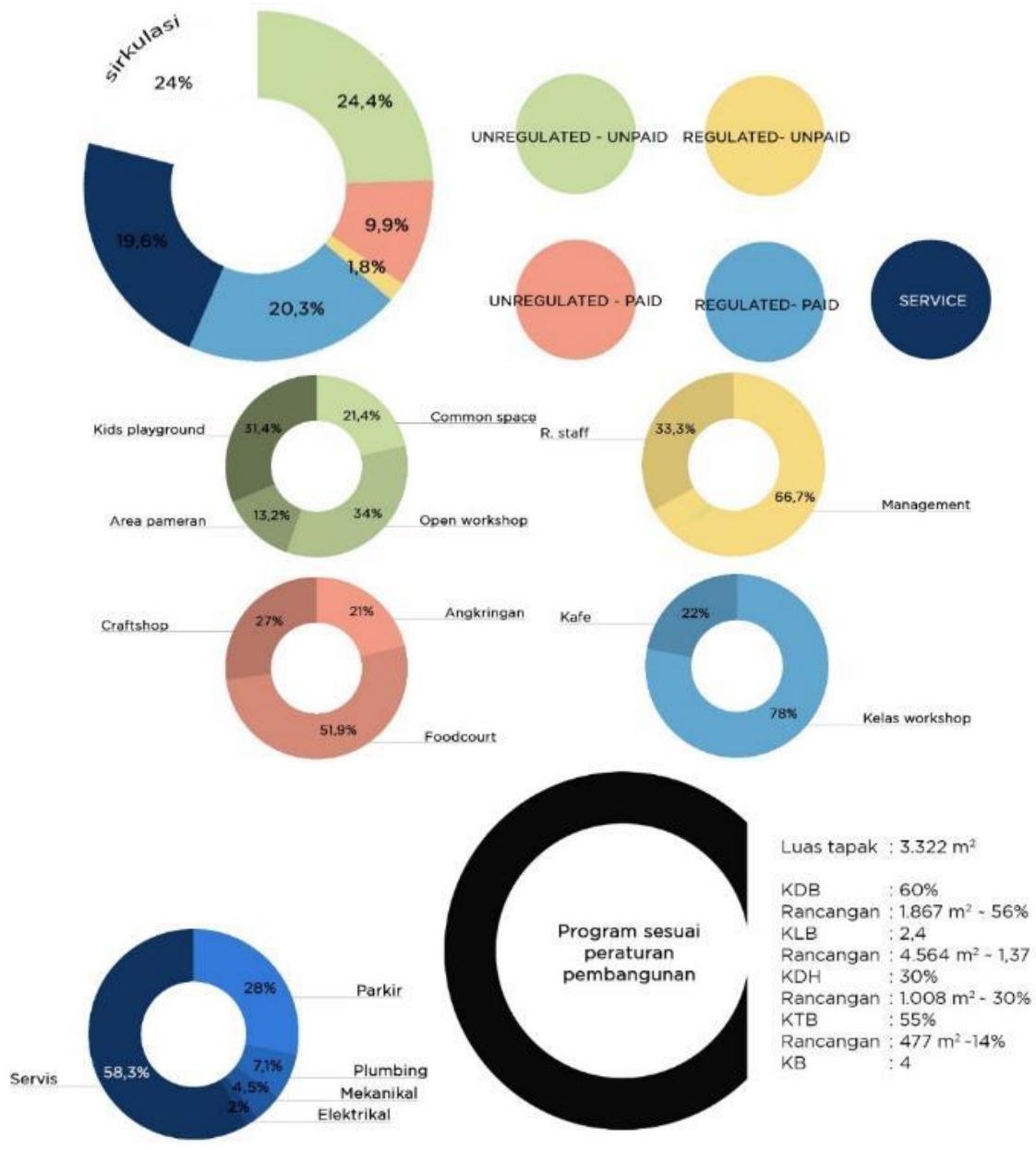

Gambar 6. Presentase program

Sumber: Penulis, 2019 


\section{Konsep}

Desain bangunan berdasarkan analisa tapak dan kawasan. Bangunan mengikuti bentuk tapak dan di desain sesuai kebutuhan runag untuk program - program yang diangkat.

1.

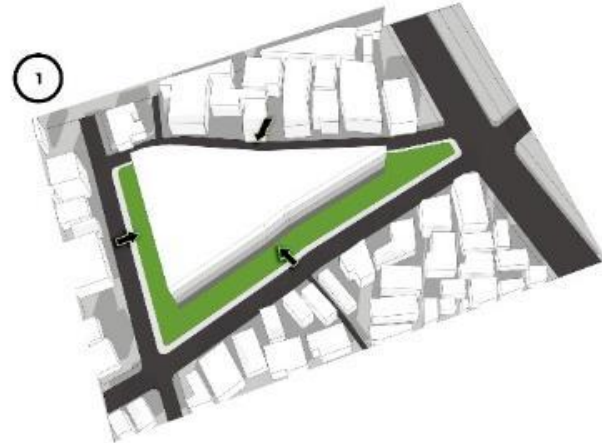

Pemaksimalan lahan

Bangunan dibentuk sesuai batas GSB

Tinggi bangunan maksimal 4 lantai

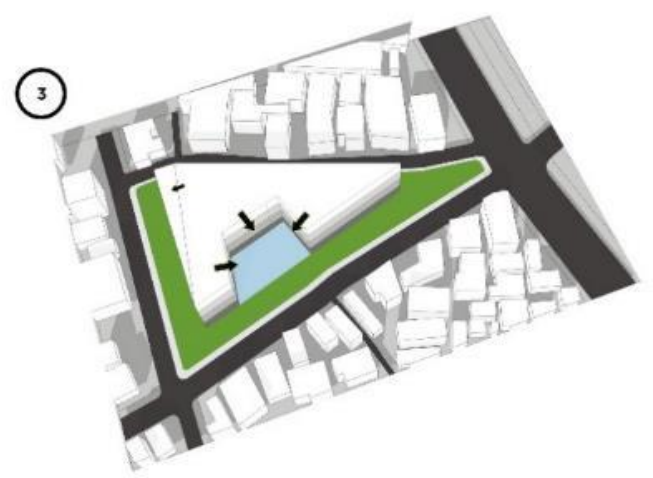

3. Penentuan entrance

Entrance utama melalui jalan utama Plaza sebagai entrance agar menerima warga sekitar

View dalam bangunan diarahkan ke plaza

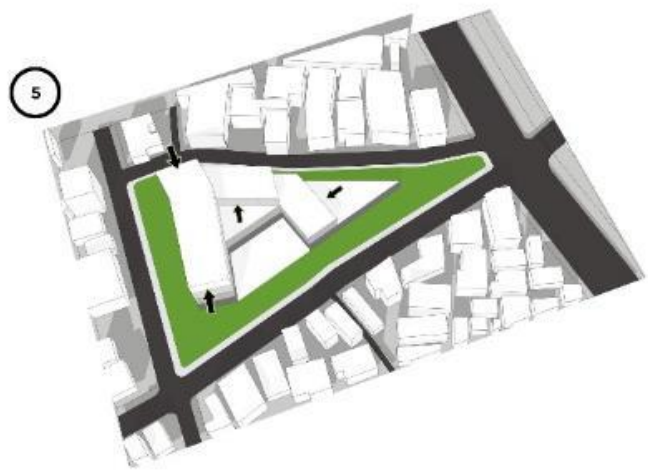

5. Pembuatan ruang efektif

Bagian sudut kecil dipotong sehingga terbentuk ruang yang lebih efektif Sesuai program yang dirancang

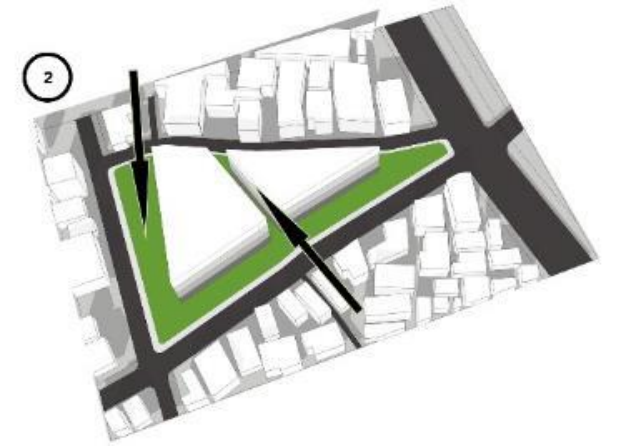

2. Penarikan sumbu jalan sekitar Garis ditarik sesuai jalan sekitar yang kemudian dijadikan posisi entrance

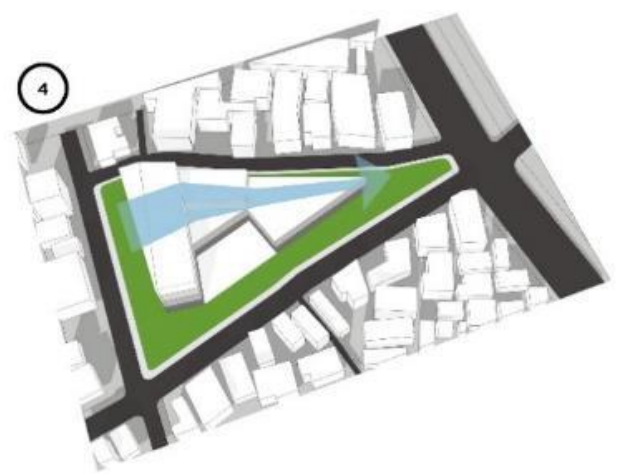

\section{Pembuatan skyline}

Tinggi bangunan dibuat sesuai bangunan sekitar yang mayoritas 1-2 lantai namun tetap memaksimalkan KLB

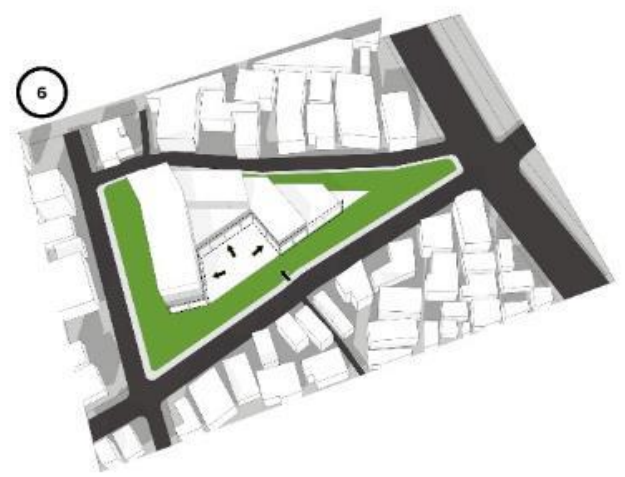

6. Pembuatan bangunan publik Lantai 1 dibuat terbuka tanpa dinding masif terutama pada bagian main entrance agar terkesan welcoming 
Ide desain Ruang Kreatif Kramat berasal dari topik proyek yaitu 'Third place' yang merupakan tempat untuk menunjang kegiatan warga suatu kawasan, dan juga kawasan itu sendiri dimana Kramat, Senen merupakan kawasan perkotaan dan sentra bisnis Jakarta Pusat. Kegiatan masyarakat sekitar dijadikan program utama bangunan. Bangunan dirancang secara kontekstual.
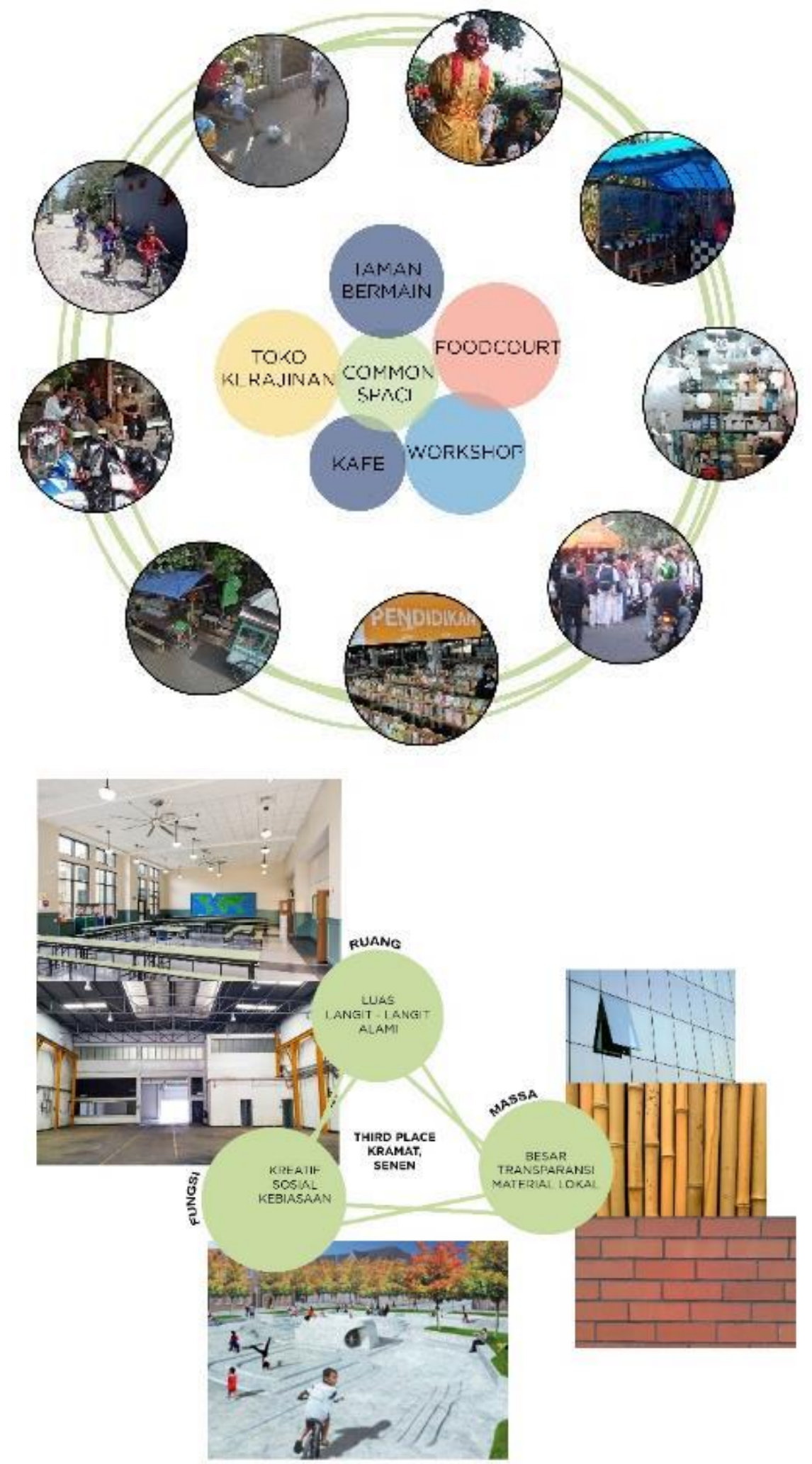

Gambar 8. Ide desain Sumber: Penulis, 2019 


\section{KESIMPULAN DAN SARAN}

Ruang Kreatif Kramat merupakan proyek arsitektur yang menjawab isu third place di kawasan Senen, Jakarta Pusat. Proyek ini hadir untuk memfasilitasi warga sekitar akan kebutuhan ruang untuk kegiatan diluar hunian dan tempat kerja. Program yang diangkat berupa kelas workshop, plaza, toko kerajinan, dan tempat nongkrong. Program - program ini muncul karena merupakan kegiatan kebiasaan warga sekitar yang dilakukan diluar jam istirahat/sekolah/kerja.

Ruang Kreatif Kramat direncanakan juga sesuai dengan peraturan yang berlaku dan berusaha tidak semakin membebani lingkungan. Bangunan memaksimalkan sumber daya alam terbarui terutama cahaya matahari dan angin. Pembangunan menggunakan produk lokal yang ramah lingkungan. Penggunaan tidak terbatas golongan dan terbuka bagi semua orang terutama warga sekitar.

Third place tercipta sesuai lingkungan yang telah dianalisa dengan cukup dalam sehingga tahap awal penelitian harus dilakukan dengan mendetail agar dapat menentukan program utama proyek. Program utama perlu didukung program penunjang namun tetap sesuai kebutuhan kawasan sehingga tidak boleh menambahkan program lain yang tidak sesuai bagi kawasan. Third place merupakan fasilitas publik sehingga bangunan sebaiknya tampak sederhana namun kompleksitas muncul pada program dan ruang yang diangkat.

\section{REFERENSI}

Gelb, S. (2015). How Successful People Spend Their Time After Work. Diakses 10 Agustus 2019 dari https://www.themuse.com/advice/10-ways-successful-people-spend-their-time-afterwork

Shahab, A. (2007) Kramat-Pasar Senen. Jakarta: Republika

Oldenburg, R. (1989). The Great Good Place. Cambridge: Da Capo Press Community Centers. diakses 25 Agustus 2019 dari https://planning.lacity.org

Architecture Design Collaborative. (2018). Architecture Design Collaborative Knows Food Halls, Completes Mall St. Matthews Renovation. Diakses 26 Agustus 2019 dari https://www.prnewswire.com

Zahn, E. (2019). Food for Thought: Dining Hall Typologies and Design Drivers. Diakses 26 Agustus 2019 dari https://asg-architects.com

Tarigan, E. (2017). Bertamu ke Kampung Ondel-Ondel di Kramat Pulo. Diakses 30 Agustus 2019 dari https://www.wego.co.id/berita/bertamu-ke-kampung-ondel-ondel-di-kramat-pulo 
